\title{
Indícios de validade do déficit relacional no Método de Rorschach para população adulta não- paciente
}

\author{
Rafad Rubens deQuerrzz Balbi Neto- UnivesidadeFederal doEsánitoSanto Vitónia, EsánitoSanto, Brasil \\ Sávio Silveira deQuirrz - UnivesidadeFederal dbEsánitoSanto, Vitóia, Esánito Santo, Brasil
}

\begin{abstract}
$\overline{\overline{R e s u m o}}$
O Método de Rorschach no Sistema Compreensivo, no que tange à população adulta de não pacientes, no Brasil, está normatizado. Estudos de metanálise transculturais sobre esses resultados apontam que a amostra brasileira apresenta os maiores valores para o Índice de D éficit Relacional (Coping D eficit Index - CDI) dentre 14 países. Logo, esta pesquisa busca indícios de validade do Índice de Déficit Relacional investigando demanda social e aspectos do relacionamento interpessoal em entrevista fenomenológica com 8 universitários avaliados como positivos para o CDI. A análise dos dados seguiu o método fenomenológico. Os resultados apontam dificuldades dos participantes em lidar com a demanda social; os relacionamentos com irmão não indicam necessariamente intimidade ou amizade, mas apenas afeto. Há distanciamento, conflito e desrespeito no relacionamento com o pai e desentendimento com a mãe. Conclui-se que os dados apontam indícios de validade do Índice de Déficit Relacional.

Palavasdhave Medidas Projetivas da Personalidade; Teste de Rorschach; Relações interpessoais; Relações familiares.
\end{abstract}

\section{Relational deficit validation evidences after Rorschach test in non-patient, adult population}

\begin{abstract}
The Rorschach Comprehensive System over non-patient, adult population in Brazil is standardized. Trans-cultural, metaanalytical assessments on those results rank Brazilian sampling as leading-Coping Deficit Index (CDI) among 14 countries. Hence, this survey seeks evidences of CDI validity, inquiring about both social requests and interactive aspects, along a phenomenological interview, where 8 undergraduates were diagnosed as CD I-positive. Data analysis followed a phenomenological method. Results reveal social difficulties of the subjects; sibling relationships do not necessarily indicate closeness or friendship, just affection. There is distancing, conflict, and disrespect in fatherly relationship, and misunderstandings in motherly relationship. It is concluded the data suggests evidences for CD I validity.

Kegnards Personality Projective Measurements; Rorschach Test; Interpersonal relationships; Family relationships.
\end{abstract}

\section{Indicios de validez del déficit relacional en el Método de Rorschach para población adulta no paciente}

\begin{abstract}
Resumen
El Método de Rorschach Sistema Comprensivo, con respecto a la población adulta de no pacientes, en Brasil, está estandarizado. Estudios de metanálisis transculturales sobre esos resultados apuntaron que la muestra brasileña presenta los mayores valores para el Índice de Déficit Relacional (Coping Defiat Indx - CDI) entre 14 países. Luego, esta investigación busca indicios de validez del Índice de Déficit Relacional, investigando demanda social y aspectos del relacionamiento interpersonal en entrevista fenomenológica con 8 universitarios evaluados como positivos para el CDI. El análisis de los datos siguió el método fenomenológico. Los resultados apuntaron dificultades de los participantes en tratar con la demanda social; los relacionamientos con hermano no indican necesariamente intimidad o amistad, pero sólo afecto. Hay distanciamiento, conflicto y desrespecto en el relacionamiento con el padre y desentendimiento con la madre. Se concluye que los datos apuntaron indicios de validez del Índice de D éficit Relacional.

Palabras dave Medidas Proyectivas de la Personalidad; Test de Rorschach; Relaciones interpersonales; Relaciones familiares.
\end{abstract}

0 Método de Rorschach é uma das formas de avaliação psicológica mais utilizadas mundialmente e sem dúvida é instrumento de destaque para os profissionais de diversas áreas da Psicologia, a exemplo da clínica, jurídica e organizacional (Nascimento, 2010; Pasian, 2002; Pianowski \& Villemor-Amaral, 2010). Recentemente foram publicadas normas para 0 Método de Rorschach no Sistema Compreensivo (SC) aplicado à população adulta não-paciente ${ }^{1}$ brasileira (Nascimento, 2007, 2010). Ao mesmo tempo, estudos recentes sobre normatização internacional do SC (Meyer, Erdberg \& Shaffer, 2007) e de metanálise transcultural (Balbi Neto \& Queiroz, 2009) apontam

1 Entende-se aqui "população não-paciente" como pessoas sem histórico de desajuste psicológico ou transtorno psiquiátrico, em atividade laboral e/ ou estudantil, incluindo atividades domésticas. que a amostra brasileira apresenta os maiores valores para medidas do Índice de Déficit Relacional positivo (CDI+) dentre 14 países. Enquanto a média internacional ocidental está em 38,71\% (DP=11,30\%) da população com CDI+, estima-se 55\% para o Brasil (Balbi Neto \& Queiroz, 2009). Ademais, as maiores porcentagens ocidentais de pessoas com $\mathrm{CDI}=4$ e 5 (35\% e 20\%, respectivamente), estão no Brasil (Balbi Neto \& Queiroz, 2009). Assim, este trabalho se inclina a investigar o Índice de D éficit Relacional na população adulta não-paciente.

Hermann Rorschach, psiquiatra suíço, em 1921 publicou o Psicodiagóstio (Rorschach, 1967), livro que trata do desenvolvimento de uma prova de interpretação de formas fortuitas - figuras pouco estruturadas. Rorschach (1967) sugere que pacientes de 
hospitais psiquiátricos apresentavam padröes de respostas semelhantes entre si, conforme 0 transtorno do qual padeciam, diferenciando-se, por outro lado, de grupos de não-pacientes. Essa prova é denominada, atualmente, Método das Manchas de Tinta de Rorschach ou, apenas, Método de Rorschach. 0 termo mátob foi adotado pois o instrumento "permite que seus dados sejam interpretados de acordo com 0 referencial teórico que se preferir" (Weiner, 2000, p. 32).

Ao longo dos anos, diversos pesquisadores no mundo investigaram o método, criando sistemas de classificação e interpretação diferentes a respeito, mas todos a partir do Psicodiagnóstico de Rorschach (1967). Este estudo toma como referência o Método de Rorschach segundo orientações do Sistema Compreensivo (Exner, 1999), que consiste em conjunto de técnicas específicas (aplicação, classificação e interpretação) baseadas no Método de Rorschach, propiciando avaliação padronizada (Exner, 1999; Exner \& Sendín, 1999).

O Método de Rorschach segundo o Sistema Compreensivo consiste na apresentação de dez pranchas com borrões de tinta indefinidos ou pouco estruturados (Weiner, 2000), sendo a primeira preta, a segunda e a terceira pretas e vermelhas. Da quarta à sétima, novamente pretas, e as três últimas, coloridas. Após a apresentação de cada prancha o participante é questionado sobre as manchas, conforme etapas e perguntas padronizadas no manual de referência (Exner, 1999).

Cada resposta do avaliado é classificada segundo: a prancha em que foi percebida, a localização na prancha, a Qualidade Evolutiva (Exner, 1999) da percepção, o fator que a determinou (D eterminante Exner, 1999), a Qualidade Formal (Exner, 1999) de percepção da mancha, o conteúdo da resposta, a Atividade Organizativa (Exner, 1999) da resposta, a popularidade da resposta (Respostas Populares Exner, 1999) e as características incomuns na resposta (Códigos Especiais - Exner, 1999), quando ocorrem.

Todas essas informações são registradas em protocolo (Sequência dos Códigos - Exner, 1999) e contabilizadas no Sumário Estrutural (Exner, 1999). No Sumário Estrutural, são calculados diversos índices, proporções, médias, razões e porcentagens, divididos em 8 agrupamentos de variáveis: 1) Processamento da Informação; 2) Mediação Cognitiva; 3) Ideação; 4) Traços Afetivos; 5) Autopercepção; 6) Relações Interpessoais; 7) Controle e Tolerância ao Estresse; e 8) Estresse Situacional, sendo de nosso particular interesse o CDI contido no sexto grupamento, Relações Interpessoais.
IndicedeDeitiat Reaaional (CDI)

$O$ Índice de Déficit Relacional (CopingDeficit Index - CDI) é medida do Sistema Compreensivo que avalia 0 déficit relacional. Essa medida se relaciona com 0 manejo da demanda das relações sociais, podendo variar de 0 a 5 (Exner \& Sendín, 1999).

Exner desenvolveu esse índice a partir de grupo com diagnóstico de depressão; a princípio acreditou tratar-se de segundo índice de depressão. Todavia, percebeu que alguns, sem diagnóstico, também se apresentavam positivos para 0 índice. Investigando melhor, Exner verificou que pessoas com diagnóstico de depressão respondiam melhor aos tratamentos focados nos problemas de relacionamento interpessoal, com menos recaídas em comparação com outros tipos de tratamento.

Ao mesmo tempo, identificou que o grupo de não-pacientes, com índice positivos, relatava dificuldades nos relacionamentos interpessoais. Portanto, o índice estudado por Exner não era um segundo Índice de Depressão, mas índice de dáfiat relacional interpessoal, atual CDI (Exner \& Sendín, 1999).

Pessoas com CDI 4 ou 5 costumam apresentar "problemas para enfrentar com eficiência as demandas comuns de seu meio social" (Exner \& Sendín, 1999, p. 163). Possuem "tendência a ter problemas na interação com os que [as] rodeiam; costumam estabelecer relações pessoais mais superficiais e pouco duradouras e podem parecer, frequentemente, mais distantes" (Exner \& Sendín, 1999, p. 163). Segundo Nascimento (2010, p. 136), CD I 4 ou 5 estaria presente na avaliação de pessoas "com menos habilidades sociais e tendência a apresentar dificuldades em seu relacionamento com 0 ambiente, especialmente na esfera social". Além disso, apresentam dificuldades para melhorar relacionamentos, que se mostram, de maneira geral, superficiais, indicando vulnerabilidade e desamparo (Nascimento, 2010).

Por outro lado, nada podemos afirmar apenas com a informação de que o índice é menor ou igual a 3 (Exner \& Sendín, 1999). Com isso, não se pode pressupor que pessoas negativas para o CDI são mais capazes de lidar com as demandas socais e possuem menos problemas interpessoais.

Para aprofundar o conhecimento sobre o CDI no Método de Rorschach, foi realizada revisão da literatura sobre o uso do mesmo, em maio de 2011. A recuperação das informações se deu com a utilização do sítio da Biblioteca Virtual em Saúde (http:/ / pesquisa.bvsalud.org/ regional/ index.php?lang =pt) na modalidade de pesquisa livre. Nessa busca foram consultadas 11 bases de dados, 5 em Ciências da Saúde (LILACS, IBECS, MEDLINE, Biblioteca 
Cochrane, SciELO) e 8 de Áreas Especializadas (BIOÉTICA, CidSaúde, DESASTRES, HISA, HOMEOINDEX, LEYES, MEDCARIB, REPIDISCA).

Foram utilizados os seguintes termos: Raschach Coping Defiat e Index; foram escolhidos, segundo Fujita (2004), para determinação de palavra-chave de artigos científicos. Conforme Sampaio, Rosa e Sabatini (1998), utilizou-se a estratégia de busca complexa descrita adiante: "Rorschach" AND "Coping" AND "Defiat" AND "Index".

A estratégia de busca enfocou as palavras no título, no resumo e no assunto dos artigos pesquisados. O critério de inclusão foi: artigo empírico de periódico indexado publicado em português, espanhol ou inglês de 1994 a 2011. Seriam excluídos dessa busca os artigos de metanálise, os estudos de caso e os artigos teóricos, bem como os publicados em outros idiomas.

Foram encontrados 7 artigos empíricos, em inglês, de 5 periódicos diferentes (Adiciones Assesmet; Psychiatry and Clinical Nerrosiences Jaumal of Bum Care and Renabilitation e Jaumal of Pessonality Assesment). Os artigos tratavam de populações diversificadas: dependentes de cocaína (Pinheiro e colaboradores, 2008), crianças e adolescentes não-pacientes (Franklin \& Cornell, 1997; Stredny \& Ball, 2005), pacientes psiquiátricos de manicômio judiciário (Young, Justice \& Erdberg, 1999), pacientes com cenestopatia oral (Honma \& cols., 2006), crianças e adolescentes com queimaduras graves (Holaday \& Terrell, 1994; Holaday \& Whittenberg, 1994), mas todos com dados relevantes sobre 0 CD I.
Essa revisão evidenciou elevada porcentagem de CDI positivo entre pacientes dependentes de cocaína (Pinheiro e colaboradores, 2008), presos com histórico de comportamento extremamente violento (Young \& cols., 1999), pacientes com cenestopatia oral (Honma $\&$ cols., 2006), crianças e adolescentes vítimas de queimaduras graves (Holaday \& Whittenberg, 1994), e dentre estas há predomínio sobre os não-resilientes (Holaday \& Terrell, 1994). Isso evidencia a carência de pesquisas sobre a validade do CDI com população adulta não-paciente, em especial no Brasil.

Considerando a necessidade de investigações do D éficit Relacional e as características psicológicas que 0 definem, este trabalho procurou apontar indícios de validade do Índice de Déficit Relacional pela investigação da demanda social e aspectos do relacionamento interpessoal em universitários avaliados positivos para o CDI.

\section{Participantes}

\section{Método}

Participaram inicialmente deste estudo 27 universitários, sendo selecionados a posteici 8 universitários positivos para o CDI (3 do sexo feminino e 5 do masculino), todos com idades entre 18 e 43 anos ( $M=22,88$ e $\mathrm{DP}=8,44)$, 1 casado e 7 solteiros. No CDI, 3 atingiram 5 pontos e 5 pontuaram 4 . A escolha inicial se deu em amostra de conveniência, pois os 27 participantes convidados constavam em banco de dados de pesquisas anteriores deste autor. Outros dados (idade, anos de escolaridade, cor de pele, tipo de instituição de ensino superior e curso superior em andamento) são apresentados na Tabela 1.

Tabela 1. Dados sociodemográficos dos participantes

\begin{tabular}{cccccccc}
\hline Participante & Sexo & Estado civil & Idade & $\begin{array}{c}\text { Anos de } \\
\text { escolaridade }\end{array}$ & Cor de pele & $\begin{array}{c}\text { Tipo de } \\
\text { IES }\end{array}$ & $\begin{array}{c}\text { Curso superior } \\
\text { em andamento }\end{array}$ \\
\hline P1 & F & solteiro & 20 & 12 anos & parda & pública & psicologia \\
P2 & F & casado & 43 & 16 anos ou mais & preta & pública & serviço social \\
P3 & F & solteiro & 19 & 16 anos ou mais & branca & pública & psicologia \\
P4 & M & solteiro & 19 & 12 anos & branca & particular & economia \\
P5 & M & solteiro & 25 & 12 anos & preta & pública & psicologia \\
P6 & M & solteiro & 18 & menos de 12 anos & não resp. & particular & contabilidade \\
P7 & M & solteiro & 21 & 12 anos & branca & particular & economia \\
P8 & M & solteiro & 18 & 12 anos & parda & pública & psicologia \\
\hline
\end{tabular}

\section{Instrumentoseprocedimento}

Utilizou-se, enquanto instrumentos, o Método de Rorschach (MR) no Sistema Compreensivo (SC), já introduzido anteriormente, e uma entrevista qualitativa, abaixo descrita. Antes da aplicação dos instrumentos, convidamos universitários que já participaram de pesquisas deste autor, mas sem os presentes instrumentos. Desses, 27 assinaram 0 Termo de
Consentimento Livre e Esclarecido em duas vias. Os instrumentos foram aplicados em 2 encontros, sendo, no primeiro, o Método de Rorschach nos moldes do Sistema Compreensivo (Exner, 1999) e, no segundo, a entrevista, ambas as sessões filmadas. 
MécobdeRarshach(MR)

O Método de Rorschach no Sistema Compreensivo foi um dos instrumentos utilizados, já que interessa investigar aspectos de relacionamento interpessoal e de demanda social de pessoas positivas para o Índice de D éficit Relacional.

O Método de Rorschach foi aplicado pelo autor desta pesquisa, sob supervisão do coautor da mesma. Durante a aplicação havia um auxiliar de pesquisa, estudante de graduação em psicologia, treinado no Sistema Compreensivo. A devolução dos resultados foi realizada pelo autor e conforme a solicitação dos participantes.

Duas pessoas classificaram todas as respostas, uma o aplicador e autor, e um psicólogo com boa experiência na utilização do teste. Esse último, que não presenciou a aplicação do teste e não tinha conhecimento da pesquisa que estava sendo realizada, efetuou a classificação de forma independente do primeiro. 0 índice de concordância de classificação das respostas entre esses dois profissionais foi de 0,92. A análise da concordância da classificação das respostas seguiu o seguinte procedimento:

- Concordância entre os dois classificadores item de codificação aceito.

- Discordância entre os dois classificadores - 0 item foi analisado por um juiz, igualmente especializado no sistema compreensivo, que decidiu entre as duas posições diferentes.

\section{Entrevista fenmendóg்a}

A entrevista fenomenológica usa roteiro de questões abertas aplicado em procedimento específico, conforme proposto por $\mathrm{G}$ omes (1997) e exemplificado em diferentes pesquisas orientadas por ele (Gomes, 1998). Nesse trabalho, os dados da entrevista foram tratados por método fenomenológico descrito mais adiante.

Os tópicos do roteiro são divididos em quatro grupos, em que 0 participante informa dados sociodemográficos (Grupo 1) e biográficos (remotos e atuais), enfocando: as demandas sociais (Grupo 3), os relacionamentos interpessoais familiares (Grupo 4), e informações que garantem a classificação do participante na condição de não-paciente (G rupo 2 Histórico pessoal). As definições do constructo investigado, Déficit Relacional, por ser objeto e fenômeno do estudo, orientaram perguntas do roteiro. Cada um dos grupos reúne os dados seguintes:

1. Scaiodamogáficos nome completo, sexo, telefone para contato, idade, email, endereço, escolaridade, ocupação, curso, instituição de ensino superior, anos de escolaridade, estado civil, cor de pele, naturalidade, nacionalidade.
2. Histónico pessoal: acompanhamento psicológico/psiquiátrico anterior e atual, doenças ou transtorno mental diagnosticado por médico, medicação, presença e histórico de sofrimento psicológico (ou mental) significante.

3. Demanda Social: descrição do que é as pessoas se aproveitarem do participante, como, de que modo evita que se aproveitem dele.

4. Rdaaionameto interpesscal: descrição do relacionamento com irmãos, irmãs, pai e mãe, passado e atual.

\section{Outrasconsideaçés sdareoprocedmeto}

Conforme referido, foram convidados inicialmente 27 universitários para participar da pesquisa; estimava-se que 14 ou 15 deles seriam positivos para o CDI, conforme as normas para população brasileira, que apontam $55 \%$ da população com CDIt. Todavia, os dados de apenas 8 participantes, classificados enquanto $\mathrm{CDI}+$, interessam a este trabalho. A seleção se deu após a aplicação de todos os instrumentos. Isso se justifica por minimizar efeitos de viés do entrevistador sobre os resultados. Acreditava-se que o desconhecimento do entrevistador sobre a positividade do CDI do entrevistado permitia procedimento mais neutro na investigação do D éficit Relacional.

Foram excluídos da análise participantes avaliados como negativo para o CDI já que, nada podemos afirmar sobre pessoas com o CD I menor ou igual a três (Exner \& Sendín, 1999). D essa forma, não faz sentido comparar pessoas classificadas como CDI+ (igual a quatro ou cinco) e CD I- (menor ou igual a três).

\section{Análisededados}

Os dados da entrevista foram analisados conforme o método da Fenomenologia-Semiótica, em que dados do tipo Capta são os tomados como prova ou indício da ordem de experienciado/ experienciando/ experienciador, em que o foco está em como a experiência é tomada, ou captada, e como o participante a descreve (Lanigan, 1997). Por outro lado, dados do tipo Data são fornecidos (não tomados) como prova ou indício, em que a "lógica é dada (data) ao fenômeno para predizer se a atribuição permanecerá ou não" (Lanigan, 1997, p. 23), da ordem de experienciador/ experienciando/ experienciado. Assim, dados qualitativos aqui trabalhados são tomados como evidência, ou seja, analisados como do tipo Capta.

Os dados da entrevista foram analisados seguindo os três passos da Fenomenologia-Semiótica (Gomes, 1997, 1998; Lanigan, 1997): descrição qualitativa, análise indutiva e interpretação. As variáveis de 
interesse da entrevista foram transcritas e analisadas conforme descrito.

O uso do método fenomenológico para estudo da validade de instrumentos psicológicos ainda é muito recente, porém 0 método fenomenológico está consolidado e legitimado no campo da pesquisa empírica em psicologia segundo estudo recente (DeCastro \& Gomes, 2011).

\section{Resultados}

Para atender ao escopo, descreveremos as repostas de participantes em 2 partes temáticas. $\mathrm{Na}$ primeira são apresentadas as categorias sobre como os participantes percebem e lidam com as demandas sociais, e na segunda, a descrição do relacionamento dos participantes com familiares. As frases em itálicos são transcrições literais das entrevistas. Em geral, são frases resumindo ou indicando as posições dos entrevistados sobre os temas abordados. Ao fim de cada citação há referência ao participante. Optou-se por não utilizar categorias previamente estabelecidas, apesar da menção às mesmas na revisão bibliográfica, já que 0 instrumento não sugere tematização dos relacionamentos interpessoais. O Anexo 1 apresenta dois quadros que resumem os resultados.

\section{Demandas sodais}

Descrevem-se adiante as 3 categorias temáticas sobre demandas sociais: "As pessoas me pedem dinheiro e favores", "A percepção do 'aproveitam-se de mim"” e "Formas de lidar com a demanda social".

1) As pessoas me pedem dinheiro e favores

A demanda social é percebida pelos participantes principalmente como pedidos genéricos (pedir favores) e específicos, como pedir dinheiro e ajuda em trabalhos de faculdade.

"Seaprovitam da minha situaçãofinanceira." (P6)

"Ofereso bastante ajuda, às veres as pesscas querem demais, para que eu faça trabalho de toob tipo como exeácios da faculdade" (P4)

2) A percepção do "aproveitam-se de mim"

Esta categoria temática é subdividida em duas subcategorias díspares: "As pessoas se aproveitam de mim" e "Não sei como as pessoas se aproveitam de mim".

a) As pessoas se aproveitam de mim

Nesta primeira categoria, os entrevistados percebem que as pessoas se aproveitam deles, o que pedem e em que situação pedem. Neste caso, existe demanda social específica percebida pelo participante.

"Se aproximam de mim para se aproximar de atras pesscas Seaproximam demim para fazer gupos de atividade acadênica" (P8) b) Não sei como as pessoas se aproveitam de mim

Já nesta segunda categoria, os entrevistados percebem que as pessoas se aproveitam deles de alguma forma, mas não sabem explicar como nem em que situação.

"Nãosei, eu sau miito besta. Acreditomitonas pesscas. A dhava queeramminhas amigas mas nãoeram" (P1)

3) Formas de lidar com a demanda social

A categoria "Formas de lidar com a demanda social" subdivide-se em 3 subcategorias: "Eu (acho que) sei dizer não", "Eu me afasto", e "Eu tenho dificuldade para dizer não".

a) Eu (acho que) sei dizer não

0 participante se percebe habilidoso o suficiente para negar pedidos que não gostaria de atender. Como estratégia, diz que não atenderá aos favores, ou sempre diz que está sem dinheiro ou pedindo moedas emprestadas para evitar que os outros lhe peçam dinheiro.

"É mito difíal eu atendar peelidos que eu gostania de reusar." (P3)

b) Eu me afasto

Outra estratégia dos entrevistados é afastar-se dos aproveitadores. Entendem que a distância evita a demanda social.

"Eu nomalmetemeafasto para eitar queas pesscas se aprovitemdemim" (P6)

c) Eu tenho dificuldade para dizer não

O participante se percebe com dificuldades para negar pedidos e favores. Em alguns momentos atende sem querer atender; em outros, consegue dizer "não" com dificuldade.

"Como sabem que eu não reauso fazem disso uma lè. Geralmentenãoligp eu faça” (P3)

\section{Rdacionamentos intenpsscais}

1) Relacionamento com os irmãos

0 relacionamento dos participantes com os irmão é descrito em duas grandes categorias: "Afetividade no relacionamento com os irmãos" e "Melhora no relacionamento com os irmãos com o tempo".

a) Afetividade no relacionamento com os irmãos

$\mathrm{Na}$ percepção dos participantes, há afetividade entre ele e os irmãos; pode haver ou não amizade e intimidade, mas carinho e afeto são marcantes neste tema. O s entrevistados compartilham com seus irmãos atividades em comum, como tarefas domésticas, viagens e conversas superficiais.

"[comminha immã mais nova] ésó convesa bestas sdbre clégjo e amigas [Nosso radacionamento é mito tranquilo de mitoaftocomda" (P7) 
b) Melhora no relacionamento com os irmãos com 0 tempo

$\mathrm{Na}$ percepção dos entrevistados, durante a infância havia muitos conflitos com irmãos, porém ao longo do tempo o relacionamento marcado por brigas e desentendimentos melhorava. Essa melhora caracteriza-se tanto pela ausência das brigas em razão do natural distanciamento dos irmãos, como pelo aumento da afetividade, descritos anteriormente.

"Mal imão fá crescendb e fá ficando mihor o redacionamentocomde" (P1)

2) Relacionamento com o pai

0 relacionamento com o pai é descrito em 2 grandes categorias: "Qualificação no relacionamento com o pai" e "Atividades agradáveis realizadas com 0 pai". No primeiro tema, "Qualificação no relacionamento com o pai", são descritas as maneiras pelas quais o participante qualifica os relacionamentos com o pai; no segundo, descrevem-se as atividades agradáveis com o pai.

a) Qualificação do relacionamento com o pai

A qualificação do relacionamento com o pai é feita em 3 subcategorias: "Intimidade no relacionamento com 0 pai", "Distanciamento no relacionamento com o pai" e "Conflito e desrespeito no relacionamento com o pai".

i) Intimidade no relacionamento com o pai

Na percepção dos participantes, o relacionamento com o pai é qualificado como de intimidade, respeito, cumplicidade e ajuda mútua.

"Mitorespeita Elemeane, faz mita cisa par mim Meapcia econversa comigo" (P8)

ii) Distanciamento no relacionamento com o pai

0 relacionamento com 0 pai também é qualificado como de distanciamento, em que há contato entre pai e filho, mas pouca intimidade ou amizade.

"Atualmente não tenho rdaainamento póximo Tenho mitocaninho masnãotenhointimidade" (P4)

iii) Conflito e desrespeito no relacionamento com 0 pai

Os entrevistados percebem que no relacionamento com 0 pai também há conflito $\mathrm{e}$ desrespeito. A agressão normalmente é percebida por parte do pai, não do filho. Os conflitos normalmente têm relação com 0 trabalhar junto, comum em empresas familiares.

"Fa mau patrãa a rdaçãofá conflitante" (P6)

b) Atividades agradáveis com o pai

Na percepção dos participantes, são diversas as atividades com o pai, como conversar, assistir televisão, ciclismo, caminhada e vôlei, sair à noite, ir à praia, passear e viajar.
"A gentealmosajunto assisteTV , sai à nate, viaja, tem mitos mmentos emfamilia." (P3)

3) Relacionamento com a mãe

0 relacionamento com a mãe é descrito aqui em 3 grandes categorias: "Afeto e proximidade no relacionamento com a mãe", "Desentendimento e respeito no relacionamento com a mãe" e "Atividades agradáveis com a mãe".

a) Afeto e proximidade no relacionamento com a mãe

0 relacionamento com a mãe é qualificado como tendo afeto, carinho, harmonia, amizade e brincadeiras. Pode haver muita ou pouca intimidade, mas sempre presente. A atividade de conversar é vista como 0 motivo para aproximação e afeto.

"Tenho mita amizade de caninha Ela é mito brincalhona. Ela tambémmeapoia." (P8)

b) Desentendimento e respeito no relacionamento com a mãe

0 relacionamento com a mãe também é qualificado como tendo desentendimentos e discussões. Esses não têm tanto 0 sentido de disciplinar e corrigir, insultar e humilhar. Nesta categoria a noção de desentendimentos vincula-se ao embate de ideias preservando a dignidade e o respeito, sem que uma das partes se sinta ofendida ou humilhada.

"Ela tem alguns pensamentos erados e eu puxo ardha dda. Pensamentos depreconcito nos rdadionametos". (P1)

c) Atividades agradáveis com a mãe

Na percepção dos participantes, as atividades com a mãe são agradáveis, dentre elas conversar, fazer compras, viajar, cozinhar e passear.

"A gente convesa, vai ao supemetado na casa de familiares amigos íntimss, ao teatro, tudb que preiso de imediatoéa da querecomo" (P3)

\section{Discussão}

A demanda social, aqui estudada na forma do "aproveitar-se de mim", é definida como o pedido de dinheiro e favores. Essa demanda ocorre de 2 formas: as pessoas se aproveitam do entrevistado, e este não sabe explicar como. Parece haver coerência entre as categorias, já que em ambas há a percepção de que as pessoas se aproveitam do participante. Todavia, de alguma forma elas se diferenciam: na primeira há a percepção de como as pessoas se aproveitam; na segunda, 0 participante se sente aproveitado, mas não sabe explicar como isso ocorre. A última situação aparentemente assemelha-se à primeira, mas com limitação da percepção do participante sobre 0 que e como ocorre. 
As formas com que os participantes lidam com a demanda social são: 1) negar os pedidos, 2) afastar-se das pessoas e 3) ter dificuldade para negar pedidos. À primeira vista, parece não haver coerência entre a primeira e a terceira categoria, ou seja, há paradoxo nos discursos dos participantes, ora assumindo que sabem negar pedidos, ora relatando suas dificuldades. Podemos considerar que tal paradoxo indica percepções situacionais diferentes. Em determinadas situações, o participante consegue negar pedidos; já em outras não tem 0 mesmo sucesso. Uma análise aprofundada das situações em que os participantes negam pedidos apontou negarem mais facilmente pedidos que se tornaram, perceptivelmente, abusivos.

A qualificação do relacionamento com os irmãos é dividida entre passado e presente. No passado havia conflitos e afetividade; no presente, melhora 0 relacionamento, mantendo-se a afetividade. 0 passado refere-se à infância e adolescência, fases em que a ambivalência acordo-desacordo é vista com normalidade, principalmente entre meninos. Já na atualidade, os relacionamentos são vistos com mais afetividade, com ou sem amizade ou intimidade. Aqui há um ponto relevante: apesar do relato de carinho e afeto, não há necessariamente amizade e intimidade com os irmãos. Parece que o participante quer desenvolver bons relacionamentos com os irmãos, mas não tem habilidade para tal. Isso indica limitações em construir bons relacionamentos interpessoais, tornando-se com isso pessoas mais superficiais, desamparadas e vulneráveis, conforme prevê a bibliografia.

A qualificação do relacionamento com 0 pai é marcado por intimidade, distanciamento, conflito e desrespeito. 0 relacionamento com 0 pai parece estar qualificado de maneira ambivalente, algumas situações com intimidade, outras com distanciamento ou conflitos. Diferentemente do que ocorreu na percepção das demandas sociais, aqui não há apenas percepções situacionais sobre 0 relacionamento com 0 pai, mas grupos diferenciados. Em um deles (composto por dois participantes) há marcadamente mais intimidade do que no outro, que relata distanciamento, conflitos e desrespeito. No grupo que relata intimidade e proximidade com 0 pai, também há conflitos e desrespeito, ou seja, a intimidade não é um fator para construção de um bom relacionamento. Além das categorias acima discutidas, ainda há a presença da categoria "A tividades agradáveis realizadas com o pai".

Os dados sobre o relacionamento com 0 pai ressaltam os problemas de relacionamento interpessoal, pois a presença de distanciamento, conflito e desrespeito é notoriamente percebida e assumida pelo participante. Evidencia-se déficit relacional nos participantes deste estudo.

A qualificação do relacionamento com a mãe é caracterizada por afeto, proximidade, desentendimento e respeito. Da mesma forma que no relacionamento com os irmãos e com os pais, o relacionamento com a mãe é marcado por ambivalências em que percepções contraditórias convivem no mesmo discurso. Essas ambivalências parecem situacionais, assim como nos outros casos, em que ora há afeto e proximidade, ora conflito e desentendimento. Diferentemente do relacionamento com o pai, inexistem conflitos ou desrespeitos, mas desentendimento e respeito. Parece que o participante sabe lidar melhor com a mãe do que com o pai, mas, de qualquer forma, há desacordo entre filhos e mães.

\section{Consideraçâes sobredados soiodemogáficos}

Os dados sociodemográficos dos participantes deste estudo parecem distanciar-se da amostra de referência brasileira. Mas, antes mesmo de apontar diferenças e semelhanças entre as amostra, é preciso considerar: 1) o escopo deste trabalho; e 2) as delimitações dos dados normativos. O estudo busca indícios de validade do construto Déficit Relacional, não sua normatização. Logo, diferenciais entre os dados sociodemográficos das amostras não cabem neste estudo, mas podem compor estudos de normatização.

Ao mesmo tempo, deve-se considerar que os dados normativos referem-se a uma população em geral, sem diferenciar positivos de negativos para 0 CDI. Por isso, tampouco se aplicam a este estudo comparações com dados apenas de pessoas positivas para o CDI. Comparações entre os dados da amostra inicial (de 27 participantes) que originaram este estudo não foram buscadas, devendo esses dados ser trabalhados posteriormente.

\section{Conclusão}

Os dados qualitativos confirmam empiricamente o constructo de Déficit Relacional, já que os participantes relatam dificuldades para lidar com a demanda social sem se afastar das pessoas. Os relacionamentos com irmão não indicam necessariamente proximidade, intimidade ou amizade, mas apenas afeto. Também há relatos de distanciamento, conflito e desrespeito no relacionamento com 0 pai e desentendimento no relacionamento com a mãe. Com isso, podemos afirmar que os dados apontam indícios de validade do Índice de Déficit Relacional. 


\section{Considerações finais}

Os dados referentes aos relacionamentos interpessoais com amigos foram investigados e analisados; todavia, foram suprimidos porque não indicaram Déficit Relacional. Entende-se que os vínculos de amizade são construídos a partir de número muito maior de opções de escolha, se comparados aos vínculos familiares. Há, portanto, tendência natural de escolher amigos com os quais não há problemas de relacionamento e de evitar amizades em desarmonia. Diferentemente, nos relacionamentos com irmãos e pais, há maior imposição das contingências sociais para a criação desses relacionamentos interpessoais com familiares específicos, com pouca ou nenhuma escolha.

\section{Referências}

Balbi Neto, R. R. Q., \& Queiroz, S. S. (2009). Metanálise de relações interpessoais no método de Rorschach em países ocidentais. Anais do I Congresso Brasileiro de Pesquisa do Reacionamento Interpesscal, Vitória, 2-15.

DeCastro, T. G., \& Gomes, W. B. (2011). Aplicações do método fenomenológico à pesquisa em psicologia: tradições e tendências. Estudos de Psicdoja (Campinas), 28(2), 153-161.

Exner, J. E. (1999). Manual de dassificação do Rarshach para o sistema compreensiva São Paulo: Casa do Psicólogo.

Exner, J. E., \& Sendín, C. (1999). Manual de interpretação do Rorschach para 0 sistema compreensivo. São Paulo: Casa do Psicólogo.

Franklin, K. W., \& Cornell, D. G. (1997). Rorschach interpretation with high-ability adolescent females: psychopathology or creative thinking? Jaumal of pessonalityassessment, 68(1), 184-196.

Fujita, M. S. L. (2004). A representação documentária de artigos científicos em educação especial: orientação aos autores para determinação de palavras chave. Reista Brasileira deEducaçãoEspeial, 10(3), 257-272.

Gomes, W. B. (1997). A entrevista fenomenológica e 0 estudo da experiência consciente. Psicooja USP, 8(2), 305-336.

G omes, W. B. (O rg.). (1998). Fenamendoga epesquisa em psicologa Porto Alegre: Editora da Universidade Federal do Rio Grande do Sul.
Holaday, M., \& Terrell, D. (1994). Resiliency characteristics and Rorschach variables in children and adolescents with severe burns. Jaumal of Bum Care\& Rehabilitation, 15(5), 455-460.

Holaday, M., \& Whittenberg, T. (1994). Rorschach responding in children and adolescents who have been severely burned. Jamal of Pescnality Assessment, 62(2), 269-279.

Honma, F., Kimura, M., Endo, S., O htsu, M., Okada, T., \& Satoh, T. (2006). O ral cenesthopathy examined by Rorschach Test. Psychiatry and Clinical Nerrosiences, 60(2), 154-159.

Lanigan, R. (1997). Capta versus data: método e evidência em comunicologia. Psiølogia: Rellexão e Cńtica, 10(1), 17-45.

Meyer, G. J., Erdberg, P., \& Shaffer, T. W. (2007). Toward international normative reference data for the comprehensive system. Jaumal of Pessanality Assessment, 89(1), S201-S216.

Nascimento, R. S. G. F. (2007). Rorschach Comprehensive System data for a sample of 409 adult nonpatients from Brazil. Jaumal of Pessonality Assesment, 89(1), S35-S41.

Nascimento, R. S. G. F. (2010). Sistema Compreensivo do Rorschach: teoria, pesquisa e normas para a população brasileira. São Paulo: Casa do Psicólogo.

Pasian, S. R. (2002). Atualizações sobre 0 psicodiagnóstico de Rorschach no Brasil: breve panorama histórico. PsicoUSF, 7(1), 43-52.

Pianowski, G., \& Villemor-Amaral, A. E. (2010). Localização e qualidade formal do Rorschach-SC no Brasil: validade com não-pacientes. PsicoUSF, 15(3), 333-343.

Pinheiro, T. R., Magalhaes, P. V. S., Wagner, A.V., Pinheiro K. A. T., Silva, R. A., \& Souza, L. D. M. (2008). Psychopathology of cocaine dependent patients in a therapeutic community. Adicions, 20(1), 73-79.

Rorschach, H. (1967). Psicodiagóstica (M. S. V. Amaral, trad.). São Paulo: Mestre Jou.

Sampaio, I. M., Rosa, C. R., \& Sabatini, A. A. Z. P. (1998). Instrução dirigida para execução de busca de dados psycLIT. Cadkmos dePsicloga, 4(1), 163168.

Stredny, R. V., \& Ball, J. D. (2005). The utility of the Rorschach coping deficit index as a measure of depression and social skills deficits in children and adolescents. Assesment, 12(3), 295-302. 
Weiner, I. B. (2000). Prinćpios da inteprtação do Rasshach São Paulo: Casa do Psicólogo.

Young, M. H., Justice, J., \& Erdberg, P. (1999). Risk factors for violent behavior among incarcerated male psychiatric patients: a multimethod approach. Assessment, 6(3), 243-258. 
Anexo 1 - Quadros resumos das categorias temáticas das repostas dos entrevistados

Seguem-se quadros com resumos esquemáticos sobre as categorias temáticas descritas no estudo. As frases em itálico e deslocadas para direita representam subcategorias temáticas.

Quadro 1.1. Resumo das categorias temáticas das repostas dos entrevistados sobre demandas sociais

As pessoas me pedem dinheiro e favores

A percepção do "aproveitam-se de mim"

Aspesscas seaprovitamdemim

Nãosi combas pesscasseaprovitamdemim

Formas de lidar com a demanda social

$\mathrm{Eu}$ (ahoque) sei dizernão

Eumeafasto

Eu terhodfiauldadepara dzer não

Quadro 1.2. Resumo das categorias temáticas das repostas dos entrevistados sobre relacionamento interpessoal com irmãos, pai e mãe

\begin{tabular}{|c|}
\hline Relacionamento com os irmãos \\
\hline Afetividade no relacionamento com os irmãos \\
Melhora no relacionamento com os irmãos com o tempo \\
\hline Relacionamento com o pai \\
\hline Qualificação no relacionamento com o pai \\
Intimidadenordacionamentocomopai \\
Distandamentonordacionamentocmopai \\
Conflitoedesrespetonordacionamentocmopai \\
Atividades agradáveis realizadas com o pai \\
\hline Relacionamento com a mãe \\
\hline Afeto e proximidade no relacionamento com a mãe \\
Desentendimento e respeito no relacionamento com a mãe \\
Atividades agradáveis realizadas com a mãe \\
\hline
\end{tabular}

Apoio institucional ao projeto: CNPq

Sobre os autores:

Rafael Rubens de Queiroz Balbi N eto é graduado e mestre em Psicologia pela Universidade Federal do Espírito Santo. Tem experiência na área de Psicologia Clínica, com ênfase em Psicoterapia e Avaliação Psicológica, atuando principalmente nos seguintes temas: Relacionamento Interpessoal e Personalidade.

Sávio Silveira de Queiroz é graduado e mestre em Psicologia, doutorado em Psicologia Escolar e do Desenvolvimento Humano pela USP, professor associado da Universidade Federal do Espírito Santo e orienta pesquisas na área de Psicologia, com ênfase em Processos Perceptuais e Cognitivos; D esenvolvimento e Saúde.

\section{Contato com os autores:}

Departamento de Psicologia Social e do Desenvolvimento, Centro de Ciências Humanas e Naturais - UFES

Av. Fernando Ferrari, no 514 - Goiabeiras - CEP 29075-910 - Vitória-ES.

E-mail: rafaelbalbineto@gmail.com 